International Journal of Biology, Pharmaey and Allied Sciences (IJBPAS)

'A Bridge Betueen Caboratory and QRendo'

WwW.iibpas.com

\title{
TRANSDERMAL DRUG DELIVERY SYSTEM: CURRENT AND FUTURE PROSPECTS OF TDDS
}

\begin{abstract}
KANDA A, DEEKSHA A, DUA J $\mathrm{S}^{*}$
Department of Pharmaceutics, Shivalik College of Pharmacy Nangal 140126 India

*Corresponding Author: Jagdeep Singh Dua: E Mail: aravibala1122@gmail.com; Ph. No. : 9417220859

Received $13^{\text {th }}$ April 2020; Revised $27^{\text {th }}$ May 2020; Accepted $22^{\text {nd }}$ July 2020; Available online $1^{\text {st }}$ Feb. 2021 https://doi.org/10.31032/IJBPAS/2021/10.2.5364
\end{abstract}

\begin{abstract}
Transdermal drug delivery system is one of the system in the controlled drug delivery category, which aim was to delivered the drug at pre-determined and controlled rate through the skin. TDDS is a painless method of delivering drugs systemically by applying onto healthy skin. So TDDS is an important delivery route that transfer precise amount of drug through the skin for systemic action. Several important advantages of TDDS: continuous input of drug with short biological half-lives, enhancement of therapeutic efficiency and maintenance of steady plasma level of the drug delivery route that transfer precise amount of drug through the skin for systemic action. Transdermal drug delivery system also known as "patches" are dosage form in which transfer of the drug through skin for local therapeutically effect. Evaluation of transdermal patches is use to check its thickness, moisture content, drug content, time of onset, time of duration, weight of patches, quality of patches, size, adhesive property and toxicological studies. This review article provides an overview of TDDS, advantages, disadvantages, limitation, components of transdermal patches, various methods of preparation of TDDS and evaluation of transdermal patches.
\end{abstract}

Keywords: TDDS, controlled rate, transdermal patch, controlled drug delivery system INTRODUCTION

The most common route of drug delivery are the oral and parenteral routes with the majority of small molecule drugs conventionally delivered orally. The oral route has the benefit of fixed doses, portability and self-administration for 
patients. For these reasons, the oral route remains the most convenient medication delivery method, but due to rapid degradation, the oral route has the disadvantage of low bioavailability. in the stomach and size-limited transport across the epithelium. TDDS is a painless method of delivering drugs systemically by applying a drug formulation onto intact and healthy skin. So transdermal delivery is an important delivery route that delivers precise amount of drug through the skin for systemic action. Avoiding first pass metabolism and other GI tract based variables such as $\mathrm{pH}$, gastric emptying time [1]. Reduction in the adverse effects associated with systemic toxicity, i.e. minimization of blood-drug concentrations with peaks and troughs [2].Transdermal drug delivery system also known as "patches". Patches are the dosage form in which transfer of the drug through skin for local therapeutically effect. Transdermal delivery should be limited to the situation in which a solvent diffuses through the different layers of the skin and into the systemic circulation for a therapeutic effect to be exercised, e.g. withdrawal symptoms using nicotine treatment. Topical distribution can be used only to describe a targeting of the skin's pathological sites, which requires reducing systemic absorption. This form of drug localization is critical for the treatment of dermatological conditions such as skin cancer, psoriasis, eczema and microbial infections where the seat of the disease is in the skin [3].

\section{History of TDDS}

In 1979, the first transdermal system was appoved by FDA is Transderm-SCOP for the prevention of nausea and vomiting during travel. The proof of the percutaneous absorption of drug can be detected by measurable blood level and excretion of the drug, metabolites in the urine through the patient's clinical reaction to the administered medication treatment [4].

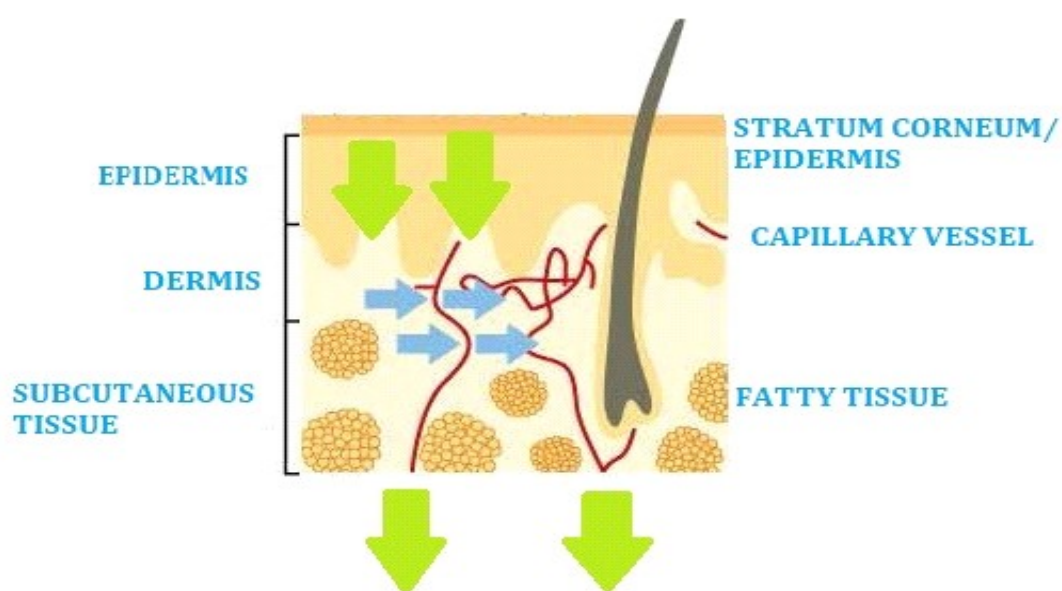

Figure 1 
The 5 ingredients used in the preparation of TDDS [5]

- Drug: Drug is in direct contact with liner for release. Ex: Nicotine, Methotrexate and Estrogen.

- Liners: During storage, they protects the patch. Ex: polyester film.

- Adhesive: hold the patch onto the skin for systemic delivery of drug. Ex: Acrylates, Polyisobutylene, Silicones. $\mid$

- Permeation enhancers: Itcontrols the discharge of the drug. Ex: Terpenes, Terpenoids, Pyrrolidones. Solvents like alcohol, Ethanol, Methanol. Surfactants like Sodium Lauryl sulfate, Pluronic F127, Pluronic F68.

- Backing layer: It protect patch from outside environment. Ex: Cellulose derivatives, poly vinyl alcohol, Polypropylene Silicon rubber.

\section{GENERATION OF TDDS [6]}

TDDS has made an important contribution to medical practice. There are 3 generation of transdermal drug delivery system [6]

\section{First-generation}

TDDS continued the rapid increase in clinical use to delivery of small, lipophillic, low-dose drugs.The first patch is liquid reservoir system where the patch is composed of a protective and adhesive backing material, a liquid drug reservoir, a release membrane.

\section{Second-generation}

In this generation, involved enhancement method include chemical penetration enhancers, gentle heating and iontophoresis. TDDS trial to enhance the delivery of organic molecules through the skin by damage its barrier function or provide some driving force for movement of molecules through the epidermis. This damage should be reversible to prevent the skin injury. But, the damage of the barrier van be difficult without causing irritation, especially when using chemical enhancers.

\section{Third-generation}

TDDS was to delivered the drug at predetermined and controlled rate through the skin. In this $3^{\text {rd }}$ generation TDDS aimed to damage the barrier to pass the large molecules into the circulation using microneedles, thermal ablation, microdermabrasion, electroporation and cavitational ultrasound.

\section{ADVANTAGES OF TDDS [7-10]}

- TDDS is painless, non-invasive way to deliver the drug directly into the systemically circulation.

- TDDS avoided the first pass metabolism and gastro-intestinal incompatibility. 
- They increase the therapeutic efficacy and decreased the undesirable side effects.

- Better patient compliance due to elimination of multiple dosing profile.

- Transdermal patches is better way to deliver drug which was brokedown by the stomach acids, not well-absorbed from the gut and degraded by the liver.

- Transdermal drug delivery system can be used as an alternative delivery system for patient who cannot tolerate oral dosage forms.

- Allows continued drug administration allowing for the use of a short biological half-life drug.

- Alternatively, if toxicity occurs from a transdermally administered drug, the effects may be moderated by removing the patch

\section{DISADVANTAGES OF TDDS [11]}

- They can't deliver ionic drugs and drugs of large molecular size.

- TDDS cannot develop if the skin is irritated by the medication or formulation.

- TDDS can't raised blood/plasma level of the drug.

- Many drugs especially drugs with hydrophilic structure permeate the skin too slowly may not achieve therapeutic level.
- The barrier function of the skin changes from one site to another site on the same person, from person to person and also with age.

\section{COMPONENTS OF TRANSDERMAL} DRUG DELIVERY SYSTEM

- Drug Reservoir/ Polymer Matrix

- Permeation Enhancers

- Pressure Sensitive adhesive (PAS)

- Backing laminate

- Release liner

- Plasticizer and solvent

Drug Reservoir/Polymer Matrix: Major part of TDDS are polymers and drug. This is prepared by dispersing the drug into liquid or solid state polymer base, which was controlled the release of drug from the device $^{[12]}$. Polymers used in TDDS should be biocompalible with drug and other components of the device, such as penetration enhancers and PSAs. They provide effective delivery of medication during the product intended shelf life and should be of stable condition.

Various polymers are used in TDDS [13]

Natural Polymers: e.g. cellulose derivatives, shellac, waxes, gums, chitosan etc.

Synthetic Elastomers: e.g. poly butadiene, poly isobutylene, silicon, neoprene, butyl rubber etc. 
Synthetic Polymers: e.g. polyvinyl alcohol, polyvinylchloride, polyethylene, polypropylene, polyacrylate, polyamide etc.

Drug: Some of the ideal properties and other facters remember when preparing TDDS are as follow:-

- The drug must be of molecular wt. less than 1000daltons.

- The drug should have associated for both lipophilic and hydrophilic phases.

- They should have a lower melting point.

Permeation enhancer: They are those substance which increase permeability of drug through skin to attain the therapeutic effect of the drug. They increase the permeability of skin by contact with structure components [14].

The ideal properties of permeation enhancer:-

- They should non- irritating, nonallergic and non-toxic in nature.

- They should be biocompability with the drug and other excipients.

- They should not provide any side effect and any adverse pharmacological activity inside the body.

Pressure sensitive adhesive: They helps to adhere transdermal patch to the skin. It can removed from the skin easily. Examples of
PSAs are:- polyacrylates, polyisobutylene and silicon etc [15].

Backing laminate: They are used as supportive material in TDDS. They impermeable to drugs and permeation enhancers, but they can chemically compalible adhesive and other excipients. Examples:- Ex-vinyl, polyethylene polyester films etc.

Release liner: It is primary packaging material. They made up of base layer and release coating layer. It should be permeable to drug, permeation enhancers and water. They can protect the transdermal patch which will remove during applied the patch on the skin.

\section{TYPE OF TRANSDERMAL PATCHES}

- Single layer drug in adhesive

- Multi-layer drug in adhesive

- Vapour patch

- Reservoir system

- Matrix system

- Drug in adhesive system

- Matrix dispersion system

- Micro-reservoir system

1] Single-layer drug in adhesive: In this patch, the adhesive layer contain a drug and not only serves to adhere the various layer together, but also responsible for the releasing the drug to the skin. The layer is enclosed with a temporary linear and a backing [16]. 
2] Multi-layer drug in adhesive: The multi-layer adhesive drug is similar to single layer adhesive drug in which both adhesive layer is responsible for the releasing of the drug. But in this addition layer of drug in adhesive, usually separated by a membrane. This patch also enclosed with a temporary linear and permanent backing [17].

3] Vapour patch: This patch are new in the market. In this type of patches, the adhesive layer not only serves to adhere the various layer together, but also responsible for releasing of the vapour.

4] Reservoir system: Membrane patches contain a delivery rate-controlling membrane between the drug reservoir and the skin. Microporous membranes, which control drug flux by the size of pores in the membrane, through which drug permeate by dissolution and diffusion, can also used. Ideally, the membrane should be permeable only to the drug and enhancer and should retain other formulation excipients [18]. various material can be used as ratecontrolling membrane; silicones, polyester elastomers, ethylene-vinyl acetate copolymers [19].

\section{5] Matrix system:}

Drug in adhesive matrix system: Here, the drug reservoir is uniformly dispersed in an adhesive polymer and then spreading the drug adhesive polymer by melting on an backing layer [20]. On above the reservoir, the unmediated polymer adhesive layer are applied for safety purpose [21].

Drug in matrix system: Here, the drug uniformly dispersed in a hydrophilic or lipophilic polymer matrix, which it diffuses to the skin surface. Three steps are involved in the drug delivery processStep 1:-Formation of crystal lattice by dissociation of drug molecules

Step 2:-Solubilization of the drug in the polymeric matrix

Step 3:-Diffusion of drug molecule through the matrix to the surface of the skin

Drug in Microreservoir: In this system, combination of reservoir and matrix-dispersion system. The drug reservoir is formed by first suspending the drug in an aqueous solution of polymer and then dispersing the solution uniformly in the lipophilic polymer to form microscopic spheres of drug reservoirs. This thermodynamically unstable dispersion is stabilized quickly by immediately crosslinking the polymer [22].

\section{Current \& Future Prospects of TDDS}

Recent technological advancements have resulted from developments in precision engineering (bioengineering), electronics, chemical engineering, and material sciences, all of which have helped to develop miniature powerful devices capable of generating the clinical response required. 


\section{Techniques For Skin Permeabilization}

Electrically Assisted Delivery- The use of electropermeabilization, as a means of increasing diffusion through biological barriers, dates back up to 100 years [23]. Electrical approaches to improve skin processes include iontophoresis and electroporation.

Iontophoresis- This method involves applying low-level electrical current either directly to the skin or indirectly through the dosage form to improve the permeation of the therapeutic agent used topically [24]. As a result of this methodology, an increase in drug permeation can be attributed to either one or a combination of the following mechanisms: electrorepulsion (for charged solutes), electro-osmosis (for uncharged solutes), and electropertubation (for both charged and uncharged).

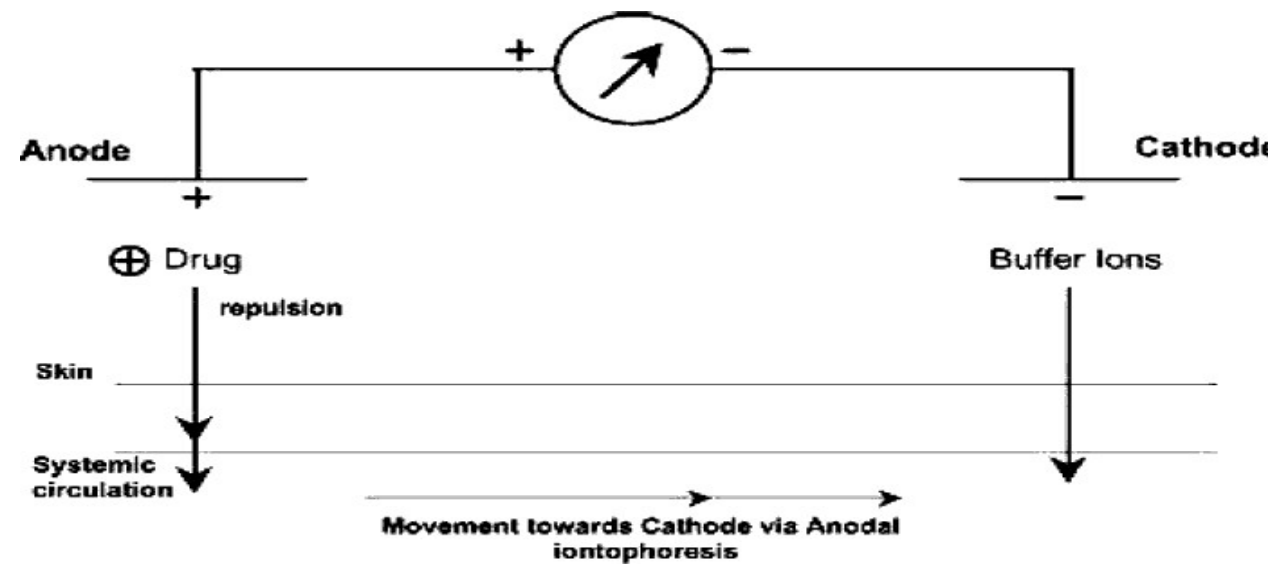

Figure 2: Basic iontophoretic set-up illustrates direction of solute movement with respect to electrode type [25]

Parameters influencing the design of an iontophoretic skin delivery system include the form of the electrode, current pressure, system $\mathrm{pH}$, competitive ion effect and the permeant form [25]. The Phoresor ${ }^{\circledR}$ device (Iomed Inc.) was the first iontophoretic system to be licensed as a physical medicine therapeutic device by the Food and Drug Administration (FDA) in the late 1970 's.Iontophoretic devices are regulatoryapproved specifically for delivering medications into the body for medicinal purposes and advanced applications such as the treatment of medical disorders (e.g., cystic fibrosis) and the regulation of glucose. Throughout the years, extensive research has been ongoing to increase patient compliance through the use of patient-friendly, compact, and effective iontophoretic systems.

These improved systems include the iontophoretic instruments Vyteris and ETRANS. The Vyteris lidocaine delivery system for local dermal anesthesia is a device allegedly removing the discomfort and other inconveniences associated with traditional anesthetic approaches such as the slow onset of operation. The delivery 
system for the Vyteris consists of a patch (two preloaded reservoirs) and a dose monitor. The main reservoir consists of a flexible adhesive pad pre-filled with the local anesthetic, lidocaine (and a vasoconstrictor, epinephrine, to maintain the active agent's therapeutic concentrations at the target site), while the other reservoir contains saline to complete the circuit. The electronic dose controller is lightweight, portable, battery-powered, simple to wear and built to provide multiple uses. A preprogrammed microcomputer forms an integral part of the electrical charge control scheme. Patch and controller connect via an interface. This delivery system may be used for other therapeutic agents; however, the FDA submitted New Drug Application (NDA) is for the delivery of lidocaine only.

Electroporation- Electroporation requires applying high voltage pulses to cause damage to the skin. Transient pores are proposed to be generated during the electroporation, which may account for increased skin permeability [26]. High voltages (almost $100 \mathrm{~V}$ ) and short durations of treatment (milliseconds) are used most commonly. Many electrical parameters influencing transmission include the pulse properties such as waveform, speed and number [27].

The technique has been used effectively to increase the skin permeability of molecules of varying lipophilicity and size (i.e. small molecules, proteins, peptides and oligonucleotides) including biopharmaceuticals with a molecular weight greater than $7 \mathrm{kDA}$, the existing iontophoresis maximum [28]. Electroporation's potential to enhance the therapeutic efficacy of an already known transdermal medication, fentanyl, has also been shown [29].

Mechanical Methods Such approaches include the use of a mechanical or physical means to penetrate or pass the SC barrier.

\section{Microneedle Based Needle}

This process was based on one of the first patents ever filed for a drug delivery system for percutaneous drug administration. The system as defined in the patent consists of a drug reservoir and a projection plurality $(50-100 \mu \mathrm{m}$ long microneedles) extending from the reservoir, penetrating the stratum corneum and epidermis to deliver the drug. The invention's numerous examples include the use of a membrane to isolate the medication from the skin, and the release of the drug from its reservoir. The reservoir can include drug, drug solution, and gel or solid particulate matter. The inventor claims the ability to bypass the barrier properties of the SC by the use of projections and also delivers the active agent either for local or systemic effect at a controlled rate. 


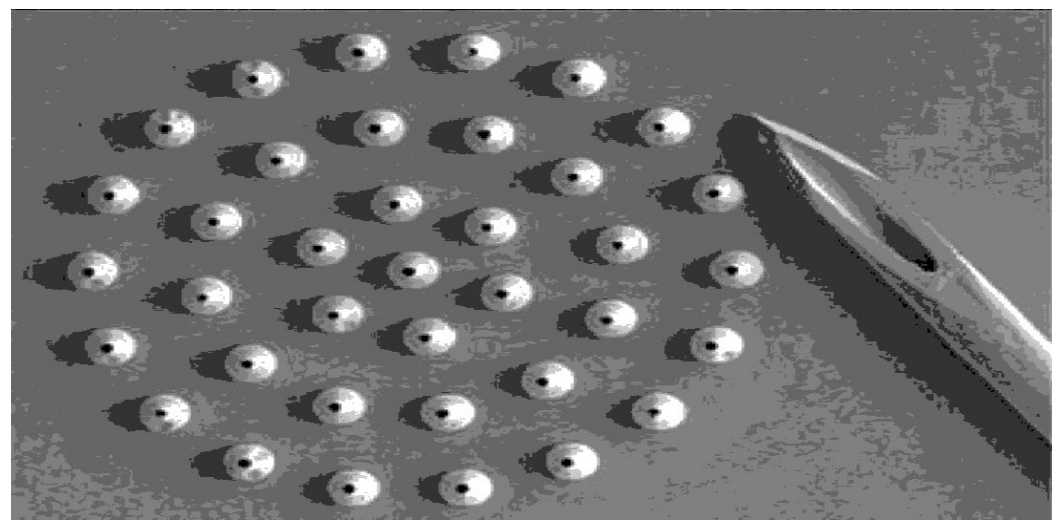

Figure 3: A microneedle array system (needles $\sim 150 \mu \mathrm{m}$ in length and fabricated from silicon) [3]

\section{Skin Abrasion}

Abrasion methods include direct removal or destruction of the upper skin layers to allow the permeation of topically applied medications. Many of these methods are based on procedures used in the treatment of acne, wounds, hyperpigmentaion and other skin blemishes by dermatologists for superficial skin resurfacing (e.g., microdermabrasion).The distribution ability of skin abrasion techniques is not restricted by the drug's physicochemical properties, and previous research has shown that these methods enhance and regulate the distribution of a hydrophilic permeant, vitamin $\mathrm{C}$, vaccines \& biopharmaceuticals [30].

\section{Skin Puncture \& Perforation}

These devices include the use of needlelike structures or blades that, when in contact with the skin, disrupt the skin barrier by creating holes and cuts resulting from a given movement and are similar to microneedle devices created by microfabrication technology.

\section{Needleless Injection}

A painless method of administering drugs to the skin is stated to require needleless injection. Over the years, several examples of both liquid (Ped-O-Jet ${ }^{\circledR}$, Iject ${ }^{\circledR}$, Biojector2000 ${ }^{\circledR}$, Medi-jector ${ }^{\circledR}$, Dermajet $\left(\right.$, Preci-jet ${ }^{\circledR}$, Injex ${ }^{\circledR}$ and Intraject $(\circledR)$ and powder have been identified. The latter system has been reported to deliver testosterone, lidocaine hydrochloride, and macromolecules like calcitonin and insulin successfully [31]. This drug-administering procedure circumvents the health, fear, and pain associated with hypodermic needles [32]. Transdermal distribution is accomplished by shooting the liquid or solid particles through the outer layers of the skin using an acceptable energy source at supersonic speeds [33]. 


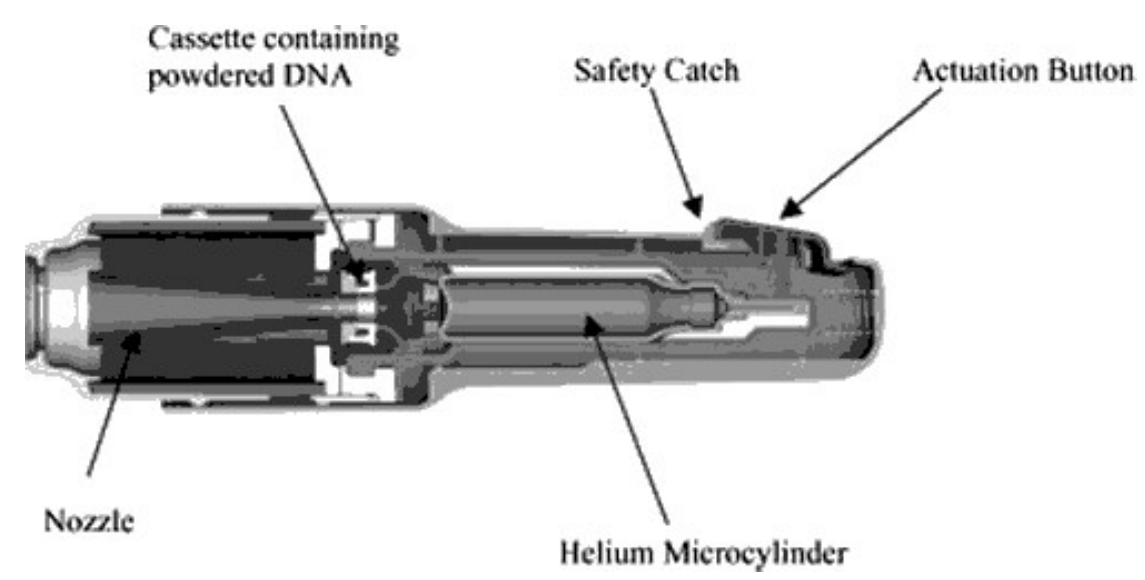

Figure 4: DNA-Particle Mediated Epidermal Delivery (PMED) device (reprinted by permission of PowderMed Ltd.) [3]

Problems facing needless injection systems involve the high developmental expense of both the unit and the dosage type and the inability to configure or monitor drug delivery to account for inter subject variations in skin permeability, unlike several of the other techniques mentioned above.

\section{CONCLUSION}

The demand for transdermal devices was valued at US\$ 2 billion (Barry 2001) and this amount reflects 10 percent of the total drug delivery industry of US\$ 28 billion. The FDA authorized the first transdermal patch in 1979, and since that time only one additional 9 drugs have been approved. A short list of "deliverables" highlights the physico-chemical constraints on the distribution of skin. The emergence of these devices will expand skin usage as a route of administration to treat a variety of conditions.

\section{REFERENCE}

[1] (Cleary 1993; Henzel and Loomba 2003; Kormic et al. 2003).
[2] (Cramer and Saks 1994; Kormic et al. 2003).

[3] Marc B. Brown, Gary P. Martin, Stuart A. Jones \& Franklin K. Akomeahhttps://doi.org/10.1080/10717 540500455975

[4] Loyd V. Allen Jr, Nicholas G. Popovich, Howard C. Ansel. Pharmaceutical dosage forms and drug delivery systems, 8th Edition., Wolter Kluwer Publishers, New Delhi, 2005 pp. 298-299.

[5] Chein Y.W. Transdermal drug delivery and delivery system. In, Novel drug delivery system, Vol. 50, Marcel Dekker, Inc., New york, 1992 pp.301381.

[6] http://www.pharmatutor.org/article/dev elopment-evaluation-transdermal-drugdelivery.

[7] Rihan Raza Ashu Mittal Puspendra Kumar Sanjar Alam Surya Prakash. Approaches and Evaluation of Transdermal Drug Delivery System. International Journal of Drug Development and Research, 2015, 7 (1): 222-233. 
[8] Pawan Jalwal, Anju Jangra, Lalita Dahiya, Yashpal Sangwan, Rajiv Saroha. A review on transdermal patches", The Pharma Research. A Journal, 2010, 3; 139-149.

[9] Ashvini S. Kadam, Mukesh P. Ratnaparkhi, Shilpa P. Chaudhary. Transdermal Drug Delivery: An Overview. International Journal of Research and Development in Pharmacy and Life Sciences. 2014, Vol. 3, No.4, pp 1042-1053.

[10] Had graft, J., Guy, R., In; Transdermal Drug Delivery, Marcel Dekker, Inc., New York and Basel, Vol. 35, 296

[11] Saurabh Pandey, Ashutosh Bandola, Ganesh Kumar Bhatt and Preeti Kothiyal. An Overview on Transdermal Drug Delivery System. International Journal of Pharmaceutical and Chemical sciences ISSN: 2277-505

[12] Ashvini S. Kadam, Mukesh P. Ratnaparkhi, Shilpa P. Chaudhary. Transdermal Drug Delivery: An Overview. International Journal of Research and Development in Pharmacy and Life Sciences. 2014, Vol. 3, No.4, pp 1042-1053.

[13] Nikhil Sharma, Bharat Parashar, Shalini Sharma, Uday Mahajan, "Blooming Pharma Industry with Transdermal Drug Delivery System. Indo Global Journal of Pharmaceutical Sciences. 2012; 2(3): $262-278$
[14] K. Ezhumalai, P. Ilavarasan, R. Murali Mugundhan, U. Sathiyaraj, AN Rajalakshmi. Transdermal Patches in Novel Drug Delivery System. International Journal of Pharmacy \& Technology Received on 14-04-2011. Accepted on 29-042011.

[15] Hiren J. Patel, Darshan G. Trivedi, Anand K. Bhandari, Dushyant A. Shah. Penetration enhancers for Transdermal Drug Delivery System: A Review. IJPI's Journal of Pharmaceutics and CosmetologyISSN 2229- 6832.

[16] Pawan Jalwal, Anju Jangra1, Lalita Dahiya, Yashpal Sangwan, Rajiv Saroha. A review on transdermal patches", The Pharma Research. A Journal, 2010, 3; 139-149.

[17] Sandhu Premjeet, Ajay Bilandi, Kataria Sahil And Middha Akanksha. Transdermal Drug Delivery System (Patches) Applications in Present Scenario. International Journal of Research in Pharmacy and Chemistry. 2011,1(4),1139-1151

[18] 3 M Drug Delivery System, www.3M.com

[19] Debjit Bhowmik, K. Rao. Pusupoleti, S. Duraivel, K P. Sampath Kumar. Recent Approaches in Transdermal Drug Delivery System. The Pharma Innovation - Journal. 2013,99-108.

[20] Saurabh Pandey, Ashutosh Badola, Ganesh Kumar Bhatt and Preeti Kothiyal. An Overview on 
Transdermal Drug Delivery System.

International Journal of

Pharmaceutical and Chemical

sciences ISSN: 2277-505.

[21] P. K. Gaur, S. Mishra, S. Purohit, K. Dave. Transdermal Drug Delivery System: A Review. Asian Journal of Pharmaceutical and Clinical Research.

[22] Vandana Yadav, Sipia Altaf Bhai.M, Mamatha Y, Prashant V.V. Transdermal Drug Delivery System: A Technical Writeup. Journal of Pharmaceutical \& Scientific innovation, received on-21/12/11. Revised on-14/01/12. Accepted on: 24/01/12.

[23] Helmstädter A. The history of electrically assisted transdermal drug delivery (iontophoresis).

Pharmazie 2001; 56: 583 587, [CSA] [PubMed], [Web of Science ${ }^{\circledR}$ ], [Google Scholar]

[24] Wang Y., Allen L.

V., Li C., Tu Y. Iontophoresis of hydrocortisone across hairless mouse skin: investigation of skin alteration.

J. Pharm. Sci 1993; 82: 11401144, [PUBMED], [INFOTRIEVE], [ CSA] [Crossref], [PubMed], [Web of Science ${ }^{\circledR}$ ], [Google Scholar]

[25] Wang Y., Thakur R., Fan Q., Michnia k B. Transdermal iontophoresis: Combination strategies to improve transdermal iontophoretic drug delivery. Eur. J. Pharm. Sci. 2005; 60: 179-191, [CSA] [Google Scholar]
[26] Banga A. K., Bose S., Ghosh T. $\mathrm{K}$. Iontophoresis and electroporation: comparisons and contrasts. Int. J. Pharm 1999;

179: 119, [PUBMED], [INFOTRIEV E], [CSA], [CROSSREF] [Crossref], [PubMed], [Web of Science ®], [Google Scholar]

[27] Weaver J. C., Vaughan T. E., Chizmadzhev Y. A. Theory of electrical creation of aqueous pathways across skin transport barriers. Adv. Drug. Del. Rev 1999; 35: 21-

39, [CSA], [CROSSREF] [Crossref], [PubMed], [Web of Science ®], [Google Scholar]

[28] Banga A. K., Bose S., Ghosh T. $\mathrm{K}$. Iontophoresis and electroporation: comparisons and contrasts. Int. J. Pharm 1999;179: 119, [PUBMED], [I NFOTRIEVE], [CSA], [CROSSREF] [Crossref], [PubMed], [Web of Science ${ }^{\circledR}$ ], [Google Scholar]

[29] Denet A.R., Vanbever R., Préat V. Sk in electroporation for topical and transdermal delivery. Adv. Drug. Del. Rev., 2004;56: 659-674, [CSA], [CROSSREF]

[Crossref], [PubMed], [Web of Science ${ }^{\circledR}$ ], [Google Scholar]

[30] Vanbever R., Langers G., Montmayeu r S., Préat V. Transdermal delivery of fentanyl: rapid onset of analgesia using skin electroporation. J. Control. Rel 1998; 50: 225-235, [CSA], [CROSSREF] [Crossref], 
[PubMed], [Web of Science ( ], [Google Scholar]

[31] Mikszta J.

A., Britingham J. M., Alarcon J., et al. Topical delivery of vaccines. Patent (serial number U.S. $\quad 6, \quad 595, \quad 947$ B1)., 2003 [Google Scholar]

[32] Muddle A. G., Longridge D. J., Sweeney P. A., et al. Transdermal delivery of testosterone to conscious rabbits using powderject (R): A supersonic powder delivery system. Proc. Int Symp. Control. Rel. Bioact. Mat 1997; 24: 713, [CSA] [Google Scholar]

[33] Longbridge D. J., Sweeney P. A., Burkoth T. $\quad$ L., Bellhouse B. J. Effects of particle size and cylinder pressure on dermal powderject $\mathbb{R}$ delivery of testosterone to conscious rabbits. Proc. Int. Symp. Control Rel Bioact. Mat. 1998; 25: 964, [CSA] [Google Scholar]. 